\title{
La evolución del personaje del villano en el cine español (1982 - 2015)
}

\section{The evolution of the villain in Spanish cinema (1982-2015)}

\author{
Rosalía Linde* \\ Universidad Complutense de Madrid, España \\ (rosalialinde@yahoo.es)
}

\author{
Ignacio Nevado** \\ Universidad Internacional de La Rioja, España \\ (joseignacionevado@gmail.com)
}

Resumen Esta investigación tiene como objetivo analizar la figura del villano en el cine español entre 1982 y 2015. Se seleccionan las películas más taquilleras de cada década, y se lleva a cabo un análisis textual de estos personajes teniendo en cuenta su evolución, valores, objetivos y relación con el protagonista. Se demostrará que la figura del villano ha experimentado cambios importantes en cada etapa analizada y que estos cambios están influidos por la situación social y cultural del país, así como por la evolución narrativa del arquetipo de la Sombra en la ficción norteamericana tanto cinematográfica como televisiva.

Abstract

This investigation analyses the figure of the villain in the Spanish movies between 1982 y 2015. It focuses on four movies for each period, particularly the ones that have been more successful. It studies their villain's evolution, moral values, targets and relationship and differences with the main character. This paper shows that the figure of the villain has experienced important changes throughout these periods and that these have been influenciated by the social and cultural situation of Spain, as well as the narrative evolution of the archetype of the Shadow in film and television American fiction.

Palabras clave

Key words
Villano, antihéroe, cine español, sociedad, evolución.

Villain, anti-hero, Spanish cinematography, society, and evolution

\footnotetext{
* Graduada en Documentación y en Comunicación Audiovisual y Máster en Patrimonio Audiovisual: Historia, Recuperación y Gestión.

** Diplomado en Interpretación actoral por el Laboratorio Teatral William Layton de Madrid.
} 


\section{Introducción y Estado de la cuestión}

El villano es una pieza clave en todo relato porque se erige como la configuración del problema. Como antagonista, se trata del principal obstáculo que debe superar el héroe para poder conseguir su objetivo. Sin embargo, aunque los villanos son siempre antagonistas, no todos los antagonistas son villanos (Seger, 2000: 124). El antagonista no se opone al protagonista por motivos perversos como el villano, sino porque así lo dicta su función narrativa en el relato, ya que "el antagonista puede ser el mejor tipo de la ciudad, aunque tenga el rol de estorbar al protagonista" (Morrell, 2008:209) en la consecución de sus objetivos.

Sin embargo, el rol del villano parte de una perspectiva maniquea basada en la oposición entre el bien y el mal, por la que héroe y villano se diferencian claramente tanto por su ética, actitud y acciones, como por su apariencia física. Vladimir Propp define la figura del "agresor" -equivalente a la del villano- como quien "lucha y persigue al héroe" y cuyo papel es el de "turbar la paz de la familia feliz, provocar una desgracia, hacer el mal, causar un perjuicio" (Propp, 2001: 40-41). Tres son las funciones básicas que engloban la acción del villano: la fechoría, el combate y la persecución (Sánchez, 2013:333).

Algunas características del villano son su esencia maligna, su egoísmo, su capacidad de manipular o dañar a los más débiles, así como un pasado traumático que lo llevó a abandonar el código moral socialmente compartido por uno aberrante o distorsionado. Suelen tener carisma y dotes para el liderazgo, son inteligentes y narcisistas, esconden sus motivos y forma de actuar de otros, son impredecibles, son capaces de ignorar la humanidad de sus víctimas y sacrificarlos, utilizan chivos expiatorios para sus propios actos, y, ante todo, tienen como principal objetivo destruir al héroe (Morrell, 2008:208-215).

Durante el cine clásico norteamericano sí se identificaba generalmente la figura del villano con la de un personaje moralmente malvado, puesto que estas películas presentaban ante todo un mensaje claro y unívoco de un relato articulado hacia el happy ending (Bordwell, Staiger y Thompson, 1985). Además, tendían a dibujarlo de modo plano, con poca caracterización o justificación narrativa a su falta de ética. Sin embargo, con la evolución al cine Postclásico, y sus protagonistas moralmente confusos y antiheroicos, la concepción maniquea de confrontación entre protagonista y villano se desdibuja. En el cine Postclásico y Contemporáneo algunos de los villanos "se conforman como protagonistas" y se realiza 
"una intensa caracterización de la figura malvada... el villano es, en el cine de hoy en día, la figura clave en su evolución, podríamos decir que incluso es más importante dentro del relato que el propio héroe" (Sánchez, 2013:207).

El villano nos atrae, puesto que "da forma a nuestra sombra, lo que negamos de nosotros mismos, nuestros deseos escondidos" (Morrell, 2008:207). Carl G. Jung definió "la sombra" como un aspecto de nuestra psicología definido por las tendencias negativas que un hombre niega tener. En el cine Postclásico o Contemporáneo es habitual que protagonista y Sombra se fundan, porque "el protagonista queda paralizado por la culpa o la duda, actúa de un modo autodestructivo, expresa deseos de muerte, se abandona a su propio éxito, abusa de su poder y se vuelve egoísta en lugar de sacrificado, con toda probabilidad podemos afirmar que la Sombra se ha apoderado de él o de ella" (Vogler, 2002: 102). Y es que en el cine Postclásico y en buena parte del cine contemporáneo el héroe se ha transformado en antihéroe, quien se encuentra muy próximo al villano en relación a la integridad de su código ético (Morrell, 2008:18). Y el villano puede llegar incluso a resultar simpático, pero siempre con unos límites que ya marcaba Aristóteles en La Poética:

(...) En primer lugar es evidente que ni los hombres virtuosos deben aparecer pasando de la dicha al infortunio, pues esto no inspira temor ni compasión, sino repugnancia; ni los malvados, del infortunio a la dicha (...) pues no inspira simpatía. (1974: 169).

Es decir, Aristóteles introduce al espectador en el relato: ¿Cómo quiere sentirse? ¿Qué espera que suceda? La Poética, mucho antes que el cine clásico de Hollywood instaurara el happy ending inequívoco, ya advertía de las historias que contravenían el buen final en el que todo tiene un sentido y el mal no triunfa.

Sin embargo el margen de movimientos del villano es amplio y el estereotipo del malvado uniforme con aspecto, acciones y pensamientos acorde con su maldad ha dejado de ser tan compacto. Ya en 1971, Elia Kazan desafía al espectador con Los visitantes donde muestra a dos muchachos, Calley y Medina, que vuelven de la guerra de Vietnam y que son, en apariencia, como cualquier americano de su edad: les gusta el fútbol americano, juegan sobre el hielo como niños, miran a las chicas, pero... se convierten en violadores. Los dos personajes se transforman en criminales, pero la sociedad tampoco es ajena a esa transformación, los envió a la guerra y eso les cambió: los espectadores se sienten como el Dr. Frankenstein queriendo y temiendo a su monstruo. Por eso, durante la película, sienten simpatía por ellos, pero también rechazo. Kazan quiso demostrar que "la maldad no es una cosa ajena a nosotros" (Tubau, 2007:192-193). 
En esta línea, las películas y series americanas han profundizado en las últimas décadas en la representación de un villano más ambiguo, más poliédrico y más cercano al proceso de identificación del espectador con él. En parte esto se debe a la asimilación de la Sombra como parte de las cuatro virtudes que todo héroe debe observar como código propio: prudencia (sabiduría), justicia, fortaleza y autodominio (Sánchez-Escalonilla, 2002:22). En principio, si las acciones del héroe se guían por estas virtudes logrará la identificación con el espectador, que admirará al protagonista y se reconocerá a sí mismo en los personajes.

Los nuevos villanos de las películas y series norteamericanas de gran éxito internacional en las últimas décadas han invadido alguna de estas virtudes para "tentar" al espectador con la identificación y, por tanto, con la paradoja de apoyar a Darth Vader. En El silencio de los corderos (Jonathan Demme, 1991), Hannibal Lecter es un psicópata, pero también es un personaje cautivador para el espectador, que se siente atraído por él. La explicación está en las virtudes del héroe. Hannibal ayuda a la agente del FBI a lograr su objetivo dramático de atrapar a otro psicópata. Es decir, toma una buena decisión ayudándola (prudencia) y gracias a su intervención se captura al psicópata (justicia). Hannibal es la sombra, pero no ejerce como tal en la historia concreta que se cuenta: su función, como recuerda Vogler, es la de mentor: ayudar al héroe (Vogler, 2002:102). El héroe, por supuesto, no libera a Hannibal, pero él se sirve de su presencia para escapar de la cárcel y asesinar a personajes que hábilmente están caracterizados como desagradables, para rebajar el impacto en el espectador. Lo mismo sucede con la serie Dexter (2006-2013): un psicópata que es policía y mata sólo a los que lo merecen (villanos) según un código autoimpuesto. Es decir, un superhéroe sin la templaza (autodominio) que caracteriza a Spiderman o Batman. Y en medio de todo este proceso de cambio de la forma de representar a la Sombra están los dos extremos: Frank Underwood en House of cards (2013-2017) se erige como la opción menos mala en un mundo sin reglas morales: la sombra impone muchos de sus valores como referencia; $y$, por otro lado, la completa metamorfosis del villano en héroe en películas de animación como Megamind (Tom McGrath, 2010) o Gru, mi villano favorito (Pierre Coffin, 2010), donde la inmersión en las virtudes heroicas es total y la sombra desaparece para quedar reducida a la expresión mínima y ridícula de la maldad: sus rasgos físicos o su forma de vestir. 


\section{Metodología: Objetivo y Herramientas}

Esta investigación tiene como objetivo definir los diferentes tipos de villanos que aparecen en una selección de películas españolas producidas entre 1982 y 2015. Se plantea que los arquetipos de villano que han resultado más populares en un periodo cinematográfico coinciden con aquellos males o miedos sociales que afectaban a la sociedad española en el momento de producción del film, que su evolución es similar a la marcada entre el cine clásico y postclásico estadounidense, y a la paulatina proximidad moral, en algunos aspectos, entre héroe y villano.

El estudio se inicia en 1982 porque la Transición política en España se da por cerrada con la victoria electoral del Partido Socialista Obrero Español en diciembre de ese año, y coincide con el sistema político del momento actual. Para facilitar el análisis se divide por décadas. Esto establece un corte claro que incluye todas las circunstancias (políticas, sociales o cinematográficas) que se producen en esos años.

De cada periodo se han seleccionado las cuatro películas más taquilleras, según los datos del Instituto de Cinematografía y Artes Audiovisuales, independientemente de su género. La finalidad es atender a aquellos villanos que, como elemento esencial al relato cinematográfico, han contribuido al notable éxito popular del film. Del último periodo y por ser más breve, se han seleccionado dos películas, lo que hace un total de catorce películas analizadas (Tabla 1 ).

Filmografía analizada (por orden cronológico)

\begin{tabular}{l|l}
\hline Título & Los santos inocentes. \\
\hline Fecha de estreno & 4 de abril de 1984 (España). \\
\hline Director & Mario Camus. \\
\hline Guión & Mario Camus, Miguel Delibes (novela). \\
\hline Productora & Ganesh Producciones cinematográficas/ Televisión española (TVE). \\
\hline Género & Drama. \\
\hline Título & El viaje a ninguna parte. \\
\hline Fecha de estreno & 15 de octubre de 1986 (España). \\
\hline Director & Fernando Fernán Gómez. \\
\hline Guión & Fernando Fernán Gómez. \\
\hline Productora & Ganesh Producciones cinematográficas/ Televisión española (TVE). \\
\hline Género & Drama, Comedia. \\
\hline
\end{tabular}




\begin{tabular}{|c|c|}
\hline Título: & La ley del deseo. \\
\hline Fecha de estreno & 7 de febrero de 1987 (España). \\
\hline Director: & Pedro Almodóvar. \\
\hline Guión & Pedro Almodóvar. \\
\hline Productora: & El Deseo/ Laurenfilm. \\
\hline Género & Comedia, Drama, Thriller. \\
\hline Título & Mujeres al borde de un ataque de nervios. \\
\hline Fecha de estreno & 25 de marzo de 1988 /España). \\
\hline Director & Pedro Almodóvar. \\
\hline Guión & Pedro Almodóvar. \\
\hline Productora & El Deseo/ Laurenfilm. \\
\hline Género & Comedia, Drama. \\
\hline Título & El día de la bestia. \\
\hline Fecha de estreno & 20 de octubre de 1995 (España). \\
\hline Director & Álex de la Iglesia. \\
\hline Guión & Jorge Guerricaechevarría/ Álex de la Iglesia. \\
\hline Productora & $\begin{array}{l}\text { Canal + España/ Iberoamericana Films Producción/ Sociedad General de } \\
\text { Televisión (Sogetel). }\end{array}$ \\
\hline Género & Acción, Comedia, Crimen. \\
\hline Título & Tesis. \\
\hline Fecha de estreno: & 12 de abril de 1996 (España). \\
\hline Director & Alejandro Amenábar. \\
\hline Guión & Alejandro Amenábar/ Mateo Gil. \\
\hline Productora & Las producciones del escorpión. \\
\hline Género & Suspense, Terror. \\
\hline Título: & La buena estrella. \\
\hline Fecha de estreno & 30 de mayo de 1997 (España). \\
\hline Director & Ricardo Franco. \\
\hline Guión & $\begin{array}{l}\text { Álvaro del Amo (diálogo), Pedro Costa (diálogo), Ricardo Franco, Ángeles } \\
\text { González Sinde, Carlos Pérez Merinero (diálogo). }\end{array}$ \\
\hline Productora & Enrique Cerezo/ Pedro Costa/ Richard Magnien. \\
\hline Género & Drama. \\
\hline Título & Torrente, el brazo tonto de la ley. \\
\hline Fecha de estreno & 13 de marzo de 1998 (España). \\
\hline Director & Santiago Segura. \\
\hline Guión & Santiago Segura. \\
\hline Productora & $\begin{array}{l}\text { Creativos Asociados de Radio y Televisión (CARTEL)/ Rocabruno S.A./ Vía } \\
\text { Digital. }\end{array}$ \\
\hline Género & Comedia, Crimen. \\
\hline
\end{tabular}




\begin{tabular}{|c|c|}
\hline Título & Los otros. \\
\hline Fecha de estreno & 7 de septiembre de 2001 (España). \\
\hline Director & Alejandro Amenábar. \\
\hline Guión & Alejandro Amenábar. \\
\hline Productora & Cruise/ Wagner Productions/ Sogecine/ Las producciones del escorpión. \\
\hline Género & Horror, Misterio, Thriller. \\
\hline Título & El orfanato. \\
\hline Fecha de estreno & 11 de octubre de 2007 (España). \\
\hline Director & J. A. Bayona. \\
\hline Guión & Sergio G. Sánchez. \\
\hline Productora & $\begin{array}{l}\text { Esta vivo! Laboratorio de Nuevos Talentos/ Grupo Rodar/ Rodar y Rodar Cine } \\
\text { y Televisión. }\end{array}$ \\
\hline Género & Drama, Misterio, Thriller. \\
\hline Título & Rec. \\
\hline Fecha de estreno & 23 de noviembre de 2007 (España). \\
\hline Director & Jaume Balagueró, Paco Plaza. \\
\hline Guión & Jaume Balagueró, Luiso Berdejo. \\
\hline Productora & Castelao Producciones/ Filmax/ Televisión española (TVE) \\
\hline Género & Horror, Misterio, Thriller. \\
\hline Título & Celda 211. \\
\hline Fecha de estreno & 6 de noviembre de 2009 (España). \\
\hline Director & Daniel Monzón. \\
\hline Guión & Jorge Guerricaechavarría (adaptación), Daniel Monzón (adaptación). \\
\hline Productora & Canal+ España/ Canal+/ La Fabrique 2. \\
\hline Género & Acción, Drama, Thriller. \\
\hline Título: & Las aventuras de Tadeo Jones. \\
\hline Fecha de estreno & 31 de agosto de 2012 (España). \\
\hline Director & Enrique Gato. \\
\hline Guión & Neil Landau (Personaje: Enrique Gato). \\
\hline Productora & LightBox Entertainment / Toro Pictures / IkiruFilms / StudioCanal. \\
\hline Género & Infantil, Animación, Aventuras. \\
\hline Título & Las brujas de Zugarramurdi. \\
\hline Fecha de estreno & 27 de septiembre de 2013. \\
\hline Director & Álex de la Iglesia. \\
\hline Guión & Jorge Guerricaechevarría, Álex de la Iglesia. \\
\hline Productora & $\begin{array}{l}\text { Enrique Cerezo Producciones Cinematográficas S.A./ La Ferme! Productions/ } \\
\text { Arte France Cinéma. }\end{array}$ \\
\hline Género & Comedia/ Horror. \\
\hline
\end{tabular}

Tabla 1. Filmografía analizada (por orden cronológico). Fuente: Elaboración propia a partir de los datos de IMDB y del Instituto de la Cinematografía y Artes audiovisuales 
De la década de los 80 se han seleccionado Los santos inocentes (Mario Camus, 1984), El viaje a ninguna parte (Fernando Fernán Gómez, 1986), La ley del deseo (Pedro Almodóvar, 1987), y Mujeres al borde de un ataque de nervios (Pedro Almodóvar, 1988). De la década de los 90 se han analizado los villanos de El día de la bestia (Álex de la Iglesia, 1995), Tesis (Alejandro Amenábar, 1995), La buena estrella (Ricardo Franco, 1997) y Torrente, el brazo tonto de la ley (Santiago Segura, 1998). De la primera década del siglo XXI se estudian Los Otros (Alejandro Amenábar, 2001), El orfanato (Juan Antonio Bayona, 2007), Rec (Jaume Balagueró y Paco Plaza, 2007), y Celda 211 (Daniel Monzón, 2009). Finalmente de la etapa 2011-2015 se atiende a los villanos de Las aventuras de Tadeo Jones (Enrique Gato, 2012) y Las brujas de Zugarramurdi (Álex de la Iglesia, 2013).

Se parte de la hipótesis que los villanos, aunque su construcción está influida por la del cine y de las series norteamericanas (la ficción audiovisual más popular en España), reflejan las preocupaciones y miedos de la sociedad española. También se demuestra que los objetivos, identidades y valores del villano son diferentes según el periodo analizado para responder a las inquietudes y retos sociales y culturales del momento histórico de su producción y lograr así un mayor atractivo para el público.

Se realiza un análisis del discurso (textual analysis) teniendo en cuenta las propuestas de teóricos clásicos de la crítica literaria, como Chatman (1990), y del análisis fílmico, como Casetti y Di Chio (1998), que se adaptan al objetivo de esta investigación. Se analizan las características del villano (género, edad, extracción social, nivel de estudios realizados) y los objetivos y valores que encarna. Después se atiende al tipo de mal que representa y su naturaleza. En este sentido tiene importancia averiguar si el villano experimenta algún tipo de lucha interna y si es malo porque un hecho traumático concreto le ha arrastrado a esa actitud. También se analiza su caracterización física (rasgos físicos en consonancia con sus acciones), si el mal actúa en solitario o cuenta con ayuda de terceros, y cómo afecta el villano al viaje y metas del héroe. Finalmente se estudia el desenlace del villano: si triunfa o es castigado. Cada una de las etapas fílmicas establecidas se contextualiza atendiendo a los aspectos políticos y sociales más destacados del momento de producción de cada una de estas películas según la documentación bibliográfica analizada. 


\section{El villano en su difícil proceso de adaptación al cambio. Los años $\mathbf{8 0 .}$}

Dos de las películas seleccionadas de la década de los 80 sitúan la trama en un contexto social rural tradicional: una en la posguerra española (El viaje a ninguna parte) y otra en la década de los sesenta (Los santos inocentes); mientras que las otras dos están ambientadas en la sociedad urbana e industrial de los ochenta (Mujeres al borde de un ataque de nervios y La ley del deseo). Esto da cuenta de una dualidad presente en esos años en España, en donde se producía un proceso de migración a las ciudades (Tezanos, 1984).

En las películas más taquilleras de los 80 predominan los villanos de mediana edad: en Los santos inocentes Iván ronda los cuarenta años y Lucía, en Mujeres al borde de un ataque de nervios, los cincuenta. Aunque también hay villanos jóvenes (Antonio en La ley del deseo) e incluso entes abstractos, como en El viaje a ninguna parte, donde el cine, como nueva forma de entretenimiento, barata y atractiva, hace peligrar la supervivencia del teatro itinerante del que viven el protagonista y su familia.

En dos de estas películas los villanos pertenecen a una clase social media-alta (Lucía e Iván). Son odiosos y crueles, siendo su caracterización algo plana; y los pobres son los personajes que reciben mayor simpatía del público, actualizándose los relatos según el paradigma de la lucha de clases.

Los villanos de clase media-alta están tipificados como personas egoístas que buscan su propio bienestar. La meta de Iván, por ejemplo, es vivir bien. Representa claramente el estereotipo de "señorito", propietario terrateniente, al que la vida le ha regalado todo y que, por tanto, es incapaz de comprender valores como el trabajo, la honradez, la fidelidad o la amistad. Su sentido de la propiedad se extiende no sólo a la tierra, sino también a las personas que habitan en ella. El caso de Lucía es diferente. Aunque despierta la reprobación del espectador, su comportamiento resulta más compresible. Se trata de una mujer atormentada por los celos y el deseo de recuperar a su ex-marido. Podría decirse que, debido a sus fuertes contradicciones morales, Lucía encarna el personaje de un antihéroe. Se plantean, desde el drama emocional y personal, las consecuencias de la ley del divorcio aprobada en 1982 (Ley 30/ 1981 de 7 de julio). Es preciso aclarar que el antihéroe no es lo opuesto al héroe, sino un tipo de héroe que "tal vez pudiera ser considerado un villano por encontrarse fuera de la ley, según la percepción social, pero hacia quien el público siente especial simpatía. Nos identificamos con estos seres extraños, forasteros en su realidad, porque todos nos hemos sentido así en algún momento" (González, 2011). 
Pese a que procede de una clase social más baja, lo mismo ocurre con Antonio en La Ley del deseo, que llega a la perturbación por la pasión y el deseo que siente por Pablo, un director y guionista de cine. Antonio está dispuesto a todo para conseguir su amor, incluso a cometer un asesinato.

El señorito de Los santos inocentes es un hombre culto, si se le compara con el resto de los personajes. Su arrogancia procede de su clase social, de igual forma que la situación de esclavitud en la que viven los sirvientes deriva de su origen. Puede afirmarse que experimenta una cierta lucha interna, puesto que, en un determinado momento se plantea si sería arriesgado obligar a Paco, su sirviente, a trabajar para él en el torneo de caza. Pero enseguida se comprueba que, en realidad, su preocupación es lo que puedan decir los demás de él. En otras palabras, actúa movido por la imagen que proyecta en su entorno, sin considerar la salud, incluso la supervivencia, de otro ser humano, características propias del villano tradicional y de un planteamiento maniqueo.

Lucía no es una mujer con formación: se trata de un ama de casa que, al dar a luz a su hijo, enloqueció. Es decir, mientras que Iván no es malo por un hecho concreto, sino simplemente porque piensa que su extracción social le da derecho a abusar de sus trabajadores, en el caso de la protagonista de la película de Almodóvar, la maldad tiene un origen exógeno. En este caso se aprecia una mayor ambigüedad en el tratamiento de Lucía como villana. Sin embargo, su vestimenta, peinado, maquillaje estrafalario y su pasado traumático -ingresada en su juventud en un hospital psiquiátrico- son evidencias de su caracterización como villana.

Tanto Iván como Lucía y Antonio representan un arquetipo. El primero al de los "señoritos" que abusan de su posición social e imponen su poder de forma tiránica a quienes están a sus órdenes. La segunda a la mujer angustiada por la soledad y la frustración en medio de una nueva concepción de la familia tradicional. Antonio es un joven atractivo, homosexual y apasionado que enloquece por amor.

En cualquiera de los casos, el mal termina siendo castigado. El personaje de Los santos inocentes es asesinado por uno de sus sirvientes que se rebela ante el sufrimiento que le ha provocado su capataz: se rompen así las cadenas con un pasado cuasi medieval. La historia de Lucía termina cuando, en el aeropuerto, amenaza a Iván con dos pistolas, es reducida por Pepa y posteriormente es detenida por la policía. No puede asimilar la nueva situación 
social y se refugia en su locura. Antonio termina suicidándose, probablemente porque se encuentra acorralado y no encuentra salida a su situación.

Estos villanos del cine español de los ochenta dan cuenta, en definitiva, de los difíciles procesos adaptativos de los españoles al cambio social y cultural (desde la aparición de movimientos pacifistas en España, a raíz de su ingreso en la OTAN, al estallido de la Movida madrileña) que se estaba experimentando en España y que exigía modificar desde costumbres a prácticas sociales e incluso el aspecto externo. Quizás la película que mejor ejemplifica esas transformaciones, aunque ambientada en otra época, es El viaje a ninguna parte. En ella el héroe, Carlos Galván, es testigo de la desaparición de su oficio y su forma de vida, lo que le conduce a la locura. Lo malo es lo moderno, la presencia del cine en la sociedad de la época acaba con las formas de vida y de teatro antiguas. Lo malo es la necesidad de adaptarse a los nuevos tiempos y a las nuevas tecnologías, abandonando las antiguas tradiciones.

\section{Villanos en la sociedad desmoralizada de los 90.}

En todas las películas de este periodo analizadas el villano es un hombre de clase media, excepto en El día de la bestia en donde el diablo toma la apariencia de macho cabrío. Los villanos son identificados enseguida por el espectador, aunque en Torrente y El día de la bestia los protagonistas son antiheroicos y, por tanto, próximos moralmente a la categoría de villanos al carecer de escrúpulos y modales. Torrente, por ejemplo, inicialmente quiere acabar con una red de narcotraficantes, pero al final de la película se comprueba que su objetivo es escaparse con el dinero. Aunque muestra cierta lealtad (a El Rafi por ejemplo) abusa del poder y es prepotente. Su aspecto es descuidado y sucio, y no es nada agraciado físicamente, por lo que resulta difícil empatizar con él.

Excepto en La buena estrella, la maldad está representada por varios personajes que llevan a cabo sus fechorías en colaboración con otros: Jorge Castro y Bosco Herranz, en Tesis; en El día de la bestia el demonio cuenta con los adoradores de Satán; Mendoza y el Francés en Torrente, el brazo tonto de la ley. Sus metas no dejan dudas de su esencia maligna y falta de ética: comercializar con el horror a través de snuff movies; condenar al infierno a todos los mortales; o enriquecerse con el tráfico de drogas, respectivamente. Salvo en el caso de Daniel de La buena estrella, que da la impresión de ser un hombre que ha llevado una vida difícil, que ha dado muchos tumbos y no se sabe realmente cuáles son sus verdaderas 
intenciones, el resto de los villanos que aparecen en las películas analizadas son malvados por propia decisión. Es más, no experimentan en ningún momento remordimientos ni se cuestionan sus acciones.

Villanos como Jorge Castro y Bosco (Tesis) o Daniel (La buena estrella) resultan atractivos. E incluso algunos participan de una relación especial con un protagonista quijotesco. Ángela, (Tesis) investiga sobre la violencia para la realización de su tesis doctoral con la ayuda de Chema, y Bosco, quien en principio la ayuda a ello y le atrae, termina convirtiéndola en víctima de su propia búsqueda. En la segunda película, Daniel experimenta una lucha interna porque, aunque parece estar celoso de Rafa, al mismo tiempo se da cuenta de la manera en que éste ayuda a Marina y le respeta por ello. Igual como ocurre en el cine de los ochenta, todos los villanos mueren: la maldad es de nuevo castigada.

En general, son seres perversos, depravados, sin escrúpulos, y aunque la belleza física no se descarta en todos los casos (por el culto al cuerpo que se da en la sociedad de entonces), queda clara su condición por el protagonismo que estos personajes adquieren. A través de ellos se denuncian todo tipo de lacras sociales, que también afectan a los protagonistas. Parece apuntar a que es el propio sistema, quien alienta y promueve la maldad.

\section{Fantasía y ambigüedad en la maldad cinematográfica del nuevo siglo}

En las películas de este periodo se aprecia que no se plantea el relato como un enfrentamiento maniqueo entre el héroe y el villano, sino que las características y motivaciones de unos y otros se confunden deliberadamente. Sin embargo, ya sea por el enfrentamiento entre vivos y muertos (Los Otros, El Orfanato, REC) o entre presos y carceleros (Celda 211), los colectivos de "buenos y malos" quedan claramente definidos. Será al término de las películas en las que se apreciará que esas fronteras no estaban tan claramente definidas. En otras palabras, el villano se ha vuelto más ambiguo y cercano al espectador.

Tanto en Los Otros como en El orfanato el espectador es víctima del desconcierto, puesto que los acontecimientos se presentan como fruto de lo inexorable. Ambas películas comparten arquetipos de los relatos góticos como los fantasmas que habitan una gran mansión y poseen una carga simbólica tremendamente poderosa: una madre que asesina a sus propios hijos, ya sea de manera intencionada, como es el caso de Grace en Los Otros; o por accidente, como le ocurre a Laura en El orfanato. 
Grace comienza comportándose como una carcelera, para posteriormente encarnar el papel de heroína y finalmente descubrirse como la verdadera villana. Con respecto al personaje de Benigna Escobedo, puede decirse que, al igual que sucede con los personajes de la señora Bertha y el señor Tuttle en El orfanato, no se presenta como una auténtica villana, sino más bien como una mentora, puesto que consigue que Laura empiece a entender y preocuparse por los niños que murieron en el orfanato. En El protegido (M. Night Shyamalan, 2000) también el villano desempeña el rol de mentor del héroe:

\begin{abstract}
La figura del mentor resulta fácilmente reconocible en cualquier sociedad, ya que se puede encontrar reflejada en la figura del padre, del profesor, del tutor. Es decir, el mentor es aquél que, con buenas intenciones, va a guiar el camino del joven héroe, ofreciéndole consejos y mostrándole la sabiduría que debe obtener para ser capaz de desarrollar sus habilidades en el futuro (Fernández, 2005:51).
\end{abstract}

Benigna representa a una pobre mujer a la que el sufrimiento ha convertido en un ser casi monstruoso; su pasado traumático y su misión catártica suavizan su percepción como villana. Lo mismo ocurre con los fantasmas de los niños: aunque asustan repetidamente a Laura hasta que consigue entenderles, en el fondo sólo buscan a alguien que cuide de ellos. Son niños abocados a un destino trágico.

En Rec también se actualiza claramente una lucha entre vivos y muertos -en este caso, infectados- pero estos no poseen la voluntad de hacer daño, son malvados por su condición de zombi. La falta de solidaridad entre los vivos, y la inmoralidad de algunos, no permiten considerar al colectivo de "vivos" como héroes bienintencionados.

En Celda 211 ocurre algo similar: los presos carecen de valores morales, aunque el protagonista, el propio Juan Oliver, un trabajador responsable, se convierte en asesino movido por la venganza. Como se puede apreciar en el nuevo siglo la maldad no se adscribe a géneros, edades o condición social: cualquiera puede ser un villano. Todo villano tiene su lado bueno y todo personaje bueno, a su vez, su arista oscura. El villano ha adquirido algunas de las cualidades del héroe: Juan busca justicia y es hombre con gran autodominio.

Excepto los presos y los infectados, el resto de los personajes que representan la villanía o cierta forma de maldad no son desagradables físicamente. Grace (Nicole Kidman) es una mujer muy atractiva y que, por su modo de vestir, da la impresión de ser discreta y con profundas creencias morales. Laura (Belén Rueda) también es muy elegante y Juan Oliver (Alberto Ammann) resulta apuesto al espectador. 
Hay muerte en todos los finales, pero sin que el bien se imponga sobre el mal. Por ejemplo, Benigna muere de una forma terrible, atropellada por un camión, ante los ojos de Laura. Pero los fantasmas de los niños consiguen su objetivo: que un adulto, Laura, acepte cuidar de todos ellos para siempre. Laura, por otro lado, se suicida y termina reuniéndose en el más allá con Simón y todos los demás niños muertos en el orfanato. En el caso de Los Otros, Grace acepta su crimen y, como si se tratase de una condena a la que se ve sometida para purgarse, decide luchar con uñas y dientes para que ningún morador en el presente les eche de la casa en la que viven. En Rec, Ángela y Pablo son infectados por el virus, y en Celda 211, a diferencia de otras películas del género, en las que la honradez de un personaje o la creencia en la justicia triunfa, aquí se produce una equiparación de ambos mundos, el carcelario y el social. Utrilla muere a manos del protagonista, es decir, de Juan, y éste es asesinado por otro preso.

En conclusión, en esta década, salvo las excepciones señaladas, los héroes se confunden con los villanos, puesto que se trata de personajes perdidos, ausentes e incapaces de aceptar su identidad. Es esta circunstancia la que les dificulta identificar la realidad a algunos y obrar de forma consecuente.

\section{Hacia la maldad por la codicia o el exceso de ambición (2011-2015)}

Las dos películas analizadas en este periodo se dirigen a públicos diferentes. Las brujas de Zugarramurdi está dirigida a una audiencia mayoritariamente adulta y Las aventuras de Tadeo Jones está destinada a todos los públicos. Comparten el género al que pueden adscribirse -fantástico y de aventuras- y que están inspiradas en producciones hollywoodienses: Las aventuras de Indiana Jones (Steven Spielberg, 1981, 1984, 1989, 2008) y Las brujas de Eastwick (George Miller, 1987). Tanto en Las aventuras de Tadeo Jones como en Las brujas de Zugarramurdi, los malos no son individuos aislados sino colectivos. En ambos casos los villanos son víctimas de su ambición desmedida.

No es casualidad que en estos cinco años aparezcan en la gran pantalla malvados que son organismos cuyo único afán es enriquecerse, como la Corporación Odysseus, en Las aventuras de Tadeo Jones. En este caso, la citada corporación está dispuesta a actuar sin escrúpulos para conseguir la llave que da acceso al tesoro de los incas. Paralelamente actúa Max Mordon, movido por las mismas aspiraciones y por los mismos valores materiales, con un añadido: se trata de un personaje que proyecta una imagen de integridad que no 
se corresponde con quien realmente es. Se trata de un hombre muy atractivo, igual que los malos de las películas de la primera década del siglo XXI. Esta característica física refuerza la imagen carismática que pretende dar ante los demás. Los villanos de esta película no experimentan ningún conflicto interno. De nuevo, el bien y el mal se bifurcan desde un planteamiento maniqueo.

Estas películas contienen muchos personajes estereotipados, pero también aspectos rompedores, especialmente visibles en Las brujas de Zugarramurdi, donde las mujeres se muestran como los seres más fuertes, en contraposición a los hombres que, en el film, se encuentran completamente indefensos. Son mujeres que no muestran signos maternales o sensibles, son independientes y capaces de manipular a los hombres. En este periodo, son las corporaciones o grandes colectivos los que ejercen el mal por ambición económica, o por exceso de ambición en sus reivindicaciones.

\section{Conclusiones}

Existe un contrato implícito entre cineastas y espectadores que condiciona la narrativa cinematográfica tanto en las tramas como en los personajes (Sorlin, 2015:13). El cine ofrece una lectura de la sociedad que se produce en su circulación, para alcanzar al espectador y provocar cierto grado de identificación con las historias que contempla. En las películas más taquilleras del cine español de las últimas décadas se puede apreciar que la caracterización de los villanos responde a conflictos en la sociedad española del momento. Pero también la representación de la sombra en estas películas ha ido en paralelo con la evolución del arquetipo del villano en producciones cinematográficas americanas con capacidad de influencia en los modos de contar. De los pequeños rasgos superficiales que hacían a la sombra menos malvada, como sucedía con el glamour de Maléfica en La bella durmiente (Clyde Geronimi, Wolfgang Reitherman, Les Clark, 1959) (Vogler, 2002:104), se ha pasado a la inmersión del villano en valores y actitudes que antes sólo eran propias del héroe. Así se ve en la evolución de estos personajes en el cine español.

En los años 80 los villanos son personas que no se adaptan a los nuevos tiempos, ni a las nuevas tecnologías, ni a la reconversión industrial, ni a la nueva configuración de la familia. No saben responder a los cambios y abandonar las formas de vida tradicionales, por lo que se enfrentan de forma errática a su destino. Son egoístas porque se aferran a su mundo, a sus propiedades, ya sean personas (los celos en La ley del deseo y en Mujeres al borde 
de un ataque de nervios) o tierras (en Los santos inocentes). En alguno de estos casos, los propietarios, los ricos, son villanos, dándose así una versión muy estereotipada y simple de la lucha de clases. Resulta fácil discernir entre malos y buenos con total claridad.

En los años 90 los malos son perversos, depravados, sin escrúpulos y reflejan todas las lacras sociales. Igual que en los 80 , los villanos son fácilmente identificables como tales: asesinos psicópatas (Tesis), ladrones, traficantes de drogas (Torrente, el brazo tonto de la ley), incluso el demonio aparece en El día de la bestia, para tentar y condenar a todos los mortales al infierno. No obstante, los protagonistas comienzan a presentar características de antihéroe, aproximándose villano y protagonista al compartir códigos morales similares. El mal parece endémico, originado en el propio sistema social y bien arraigado en él (algunos villanos son atractivos y esconden sus intenciones gracias a que ostentan cargos de poder).

En la primera década del siglo $X X I$, esta frontera entre héroe y villano termina de desdibujarse. Los villanos son parte de un colectivo (fantasmas, infectados, presos) claramente identificado como villano en cuanto a su estereotipo, pero o bien sus motivaciones no son malignas per se (Rec, Los otros o El orfanato), o sus acciones quedan justificadas moralmente (Los otros o El orfanato); o bien la maldad del antihéroe es tan próxima a la suya que resulta difícil distinguirlos (Rec o Celda 211). Como ocurre en el film Los visitantes de Elia Kazan, ya no es tan sencillo distinguir entre buenos y malos en un sentido profundo y complejo. La primera década del siglo XXI estuvo marcada por los atentados terroristas del $11 \mathrm{~S}$ y $11 \mathrm{M}$, en estos episodios resulta aparentemente fácil dividir en dos bandos a héroes y villanos, pero se dificulta la tarea de identificar al verdadero villano puesto que se esconde a plena vista.

En los últimos años, la codicia y la presencia de reivindicaciones sociales se han incorporado en el cine en forma de villanos. Estos guiones reflejan la preocupación de la sociedad por el aumento de la corrupción en España o una advertencia frente a la radicalización de determinados movimientos de género. Los malos se representan en forma de colectivos: una corporación empresarial (Las aventuras de Tadeo Jones) o agrupaciones informales (Las brujas de Zugarramurdi), aunque este rasgo ya aparece en la etapa anterior con la presencia de presos, infectados o fantasmas. 
En definitiva, aunque en todos los periodos analizados los guiones siguen siendo muy aristotélicos, es decir, la maldad siempre es castigada, sea del villano o el protagonista, se observa que las fronteras entre el héroe y el villano son cada vez más difíciles de identificar. Por un lado, el guión, como toda narración y toda representación es un relato-metáfora de la vida. Y busca irremediablemente la conexión entre la historia vivida y la historia contada, la necesita y la manipula para alcanzar cierta superioridad sobre la realidad: lo que sucede en la vida a veces es absurdo e incoherente; en cambio, en el relato ficcional todo se interpreta y se otorga un significado (Ortiz, 2011:64). El espectador (y el autor) saben que significado quieren sobre el mal: la Sombra no puede ganar al final. Pero, por otro lado, el villano ya no es un elemento extraño, sino que es parte de lo que somos. Eso hace que los espectadores ya no sepan si detrás de la máscara del arquetipo de la Sombra se esconde alguien con el que vas a disfrutar o alguien que te va a hacer sufrir. Los villanos se han convertido en personajes más semejantes a lo que somos y a lo que vivimos para ayudar a que el público, al entrar a un cine, tenga el ánimo de decir: "[n]os hemos reunido todos aquí para experimentar una comunión, para descubrir de una vez qué es lo que pasa en este mundo" (Mamet, 2001: 34-35).

Referencias Aristóteles. (1999). La Poética. Madrid: Gredos (edición de Valentín García Yebra).

Bordwell, D., Staiger, J., y Thompson, K. (1985). The classical Hollywood cinema. New York: Columbia University Press.

Casetti, F. y Di Chio, F. (1998). Cómo analizar un film. Barcelona: Paidós.

Chatman, S. (1990). Historia y discurso. La estructura narrativa en la novela y el cine. Madrid: Taurus.

Fernández, E. (2005). El itinerario del héroe mitológico en la cinematografía actual. Madrid: Universidad Complutense.

González, J.F. (2011). "Héroes, antihéroes y villanos en el Western español". Razón y palabra, no 78, noviembre - enero.

Mamet, D. (2001). Los tres usos del cuchillo. Sobre la naturaleza y la función del drama. Barcelona: Alba. Morrell, J. (2008). Bullies, Bastards And Bitches: How To Write The Bad Guys Of Fiction. Ohio: Writer's Digest Books.

Ortiz, P. (2011). El guión cinematográfico: actualización de sus bases teóricas y prácticas. Zaragoza: Universidad de Zaragoza.

Propp, V. (2001). Morfología del cuento. Barcelona: Akal.

Sánchez, M. (2013). "La expresión de miedos sociales a través del villano en el cine postclásico: un análisis del texto narrativo". Revista Aequitas: Estudios sobre historia, derecho e instituciones, (3), 329-344. 


\section{LA EVOLUCIÓN DEL PERSONAJE DEL VILLANO EN EL CINE ESPAÑOL (1982 - 2015). Rosalía Linde e Ignacio Nevado}

Sánchez-Escalonilla, A.(2002). Guión de aventura y forja de un héroe. Barcelona: Ariel

Seger, L. (2000). Cómo crear personajes inolvidables: guía práctica para el desarrollo de personajes en cine, televisión, publicidad, novelas y narraciones cortas. Barcelona: Paidós Ibérica

Sorlin, P. (2015). Introduction à une sociologie du cinema. París: Klincksieck.

Tezanos, J. F. (1984). “Cambio social y modernización en la España actual”. Reis, (28), 19-61.

Tubau, D. (2007). Las paradojas del guionista. Reglas y excepciones en la práctica del guión. Barcelona: Alba.

Vogler, C. (2002). El viaje del escritor. Barcelona: Ediciones Robinbook.

Cómo citar Linde, R. y Nevado, I. (2016). "La evolución del personaje del villano en el cine español (1982-2015)”. Comunicación y Medios, 25 (33), 55 - 72. 